\title{
Research on the impact echo technique of quantitative detecting the pre-stressed conduct grouting pumpness
}

\author{
ZHANG Ke-chao ${ }^{1,2}$, Li Wang-xin ${ }^{3}$, QU Guang-zhen ${ }^{3}$, ZHONG Jun ${ }^{3}, Z H O U$
}

\author{
Guang- $-1 i^{3}$
}

\author{
,CHEN Jian-zhang ${ }^{1,2}$ \\ (1.Research Institute of Highway, Beijing China, 10088; 2. Beijing Gongke Bridge Technology \\ Co.,Ltd.R, Beijing China, 10088; 3.Shandong Transportation Research Institute. Jinan \\ 250031 ,China )
}

Key words: Grouting fullness, method of quantitative detecting, impact echo technique, pre-stressed pipe, bridge engineering

Abstract:The internal prestressed conduct grouting condition is the key problem in prestressed con crete girder bridge throughout the whole service life. Howeverm, there is no set of certain mature an $\mathrm{d}$ reliable detection technology. This paper based on the impact echo theory, through the precision a cquisition of the impact echo time of the prestressed pipe under the condition of different grouting $\mathrm{c}$ ondition levels. By establishing the relationship model between the grouting fullness degree and the reflection time of the impact echo, to provide the quantitative and accurate of measurement of the $f$ ull degree of prestressed pumpness detection technique, and service for the maintenance and rehabil itation of bridge engineering. Under laboratory conditions, set the measuring line and measuring point, application of impact echo equipment and calculation models for the detection of grouting plumpness of test beams. The drilling results show: the relative error is better than $5 \%$ pre-stressed pipeline grouting plumpness measurement, can satisfy the precision of engineering test requirements.

\section{Introduction}

It's generally believed that the deficiency of mortar in pre-stressed pipe is ubiquitous. That produces a lot of diseases such as the corrosion of pre-stressed steel, the stress concentration of anchor head, the loss of pre-stressed as time goes on and so on. It may affect the stress state of the structure, reduce the bearing capacity of bridges, affect the service life of bridges if not detect the using state of pre-stressed steel and evaluate its impact on structural durability. Thus pre-stressed pipe of pre-stressed bridge grouting quality testing is an important segment to ensure the quality of the bridge to satisfy the design requirements and the operation of the reasonable stress state. Pre-stressed steel belongs to concealed work, and grouting quality control is usually only in the pouring process and pouring site. Once the concrete pouring molding, it can not be possible to detect the existence of quality problems. It also increases the cost of future bridge maintenance.

The main methods of detecting the density of slurry in the pre-stressed steel pipe include: impact echo method, ultrasonic method, ground penetrating radar method, ray method, etc. They have their own characteristics ${ }^{[1]}$. The impact echo method have the advantage that not affected by 
the metal pipeline, large measuring range and low operating environment requirements. But the most of existing technology using fast Fourier transform (FFT) can be transformed time domain waveform into amplitude spectrum, so as to obtain the transducer received impact echo frequency. For the judgment of defects still stuck in there, or by experience generally determine the size and position of defects. It is still in the qualitative phase of the defect, which makes the test and results have been unsatisfactory. This study is based on the principle of impact echo, through establish grouting plumpness of pre-stressed pipe and the relation model of impact echo bottom reflection time to present a quantitative method which used for the detection of grouting plumpness in pre-stressed pipe ${ }^{[2,3]}$

\section{The establishment of calculation model for the grouting plumpness of pre-stressed pipe}

\section{Arrangement of measuring line and measuring point}

\section{(1) Calibration line}

Arrangement of concrete member calibration line 1along the pre-stressed steel direction on the top surface of concrete member. In order to avoid pre-stressed pipe, line 1 is located at the edge of the distance component 10 20 cm.Line 1 also can be arranged on the surface of the concrete member corresponding to the middle position of the middle axis of the two pre-stressed pipelines. The length of the line should not be less than the length of the pre-stressed pipe. Uniform set points on the calibration line, and the distance of the measuring points should between $10 \sim 20 \mathrm{~cm}$. As shown in Figure $1^{[4]}$.

\section{(2) Detection measuring lines}

Measuring line 2 is arrange on the location of the pre-stressed pipe of the concrete member's top surface. The length of line 2 is equal to the length of the pre-stressed pipe. Uniform set points on the calibration line 2 , and the distance of the measuring points between $10 \sim 20 \mathrm{~cm}$. As shown in Figure 1.

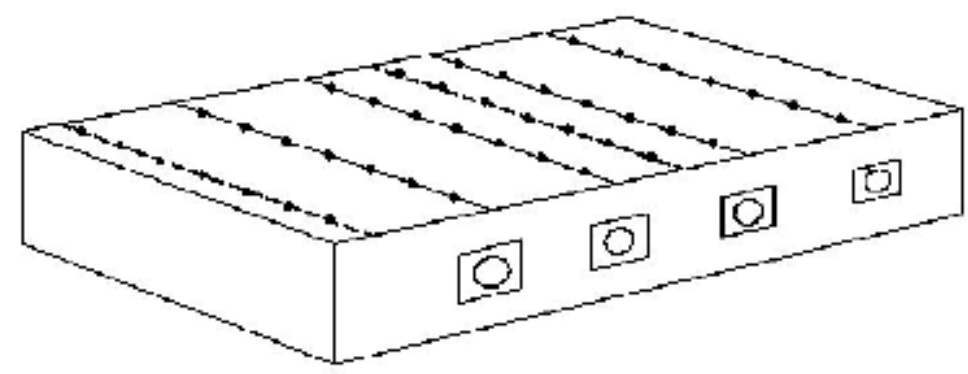

Fig. 1. Calibration test line and measurement line of concrete component (notes: 1 is the calibration line, 2 is the detection line, represents the measuring point)

\section{The average reflection time tp of impact echo of concrete structures}

Taking the precast concrete component as the trial object, set the low frequency stress pulse excitation device and the low frequency stress pulse receiver at the measuring point of measuring line 1 . When the low frequency stress pulse receiving device receives the resonance wave signal, 
the impact echo bottom reflection time $t_{\mathrm{pi}}$ of the concrete member is recorded. Move low frequency stress pulse excitation device and low frequency stress pulse receiving device along with the concrete component simultaneously, and it can be used to measure the echo reflection time at each measuring point and calculate its average value which is named as impact echo bottom average echo time $t_{p}$.

\section{The reflection time of impact echo of pre-stressed pipeline $t_{i}$}

In order to measure the pre-stressed pipeline, a low frequency stress pulse excitation device and a low frequency stress pulse receiving device are installed at the measuring points of the impact echo line 2 of the pre-stressed pipeline. It produces low frequency stress pulses that propagate back into the interior of the structure and reflected back to the bottom of the member. The stress wave is reflected back and forth between the top surface of the member, the inner part of the pipe, and the bottom surface of the member. When the bottom reflection time $t_{i}$ of the resonance wave obtained, the low frequency stress pulse excitation device and the low frequency stress pulse receiving device are simultaneously moved along the impact echo line 2 in the pre-stressed pipeline. Finally, the $t_{i}$ value of each measuring point should be measured.

\section{The calculation model of the grouting fullness of pre-stressed pipe}

Determine the pre-stressed pipe without grouting and grouting under the condition of $50 \%$ and $100 \%$ (as shown in Figure 2), according to the 1.3 and 1.4 obtain the impact echo bottom reflection time $t_{p}$ of concrete member and the impact echo bottom reflection time $t_{i}$ of pre-stressed pipe, it can confirm that the relationship between the specific value of $t_{i}$ and $t_{p}$ with grouting plumpness. Then, it could get the relation curve by fitting. Finally, according to the calibration results, the calculation model of the grouting fullness of pre-stressed pipe is obtained. As shown in equation 1:

\section{$\mathrm{f}=\mathrm{Kt}+\mathrm{b} \quad$ (equation 1$)$}

Where $\mathrm{f}$ is the grouting fullness of pre-stressed pipe (\%); $\mathrm{K}$ is the time coefficient; $\mathrm{t}$ is the specific value of the impact echo bottom reflection time $t_{i}$ of pre-stressed pipe with the impact echo bottom reflection time $t_{p}$ of concrete member; $b$ is a relation constant; Among them, when $f \geq 100 \%$, $\mathrm{f}=100 \%$, when $\mathrm{f} \leq 0 \%, \mathrm{f}=0 \%$.

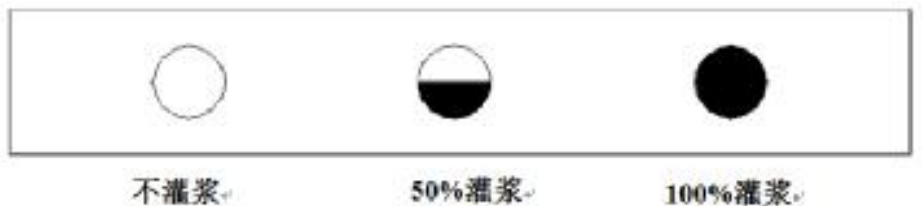

Fig. 2. Conditions for grouting of pre-stressed pipe

The following is a pipeline $80 \mathrm{~mm}$ diameter of plastic corrugated pipe, the calculation model of grouting fullness:

$$
\mathrm{f}=-4.9834 \mathrm{t}+6.7957 \text { (equation 2) }
$$

Where $\mathrm{K}=-4.9834 ; \mathrm{b}=6.7957$; when $\mathrm{f} \geq 100 \%, \mathrm{f}=100 \%$, when $\mathrm{f} \leq 0 \%, \mathrm{f}=0 \%$.

As shown in Figure 3: 


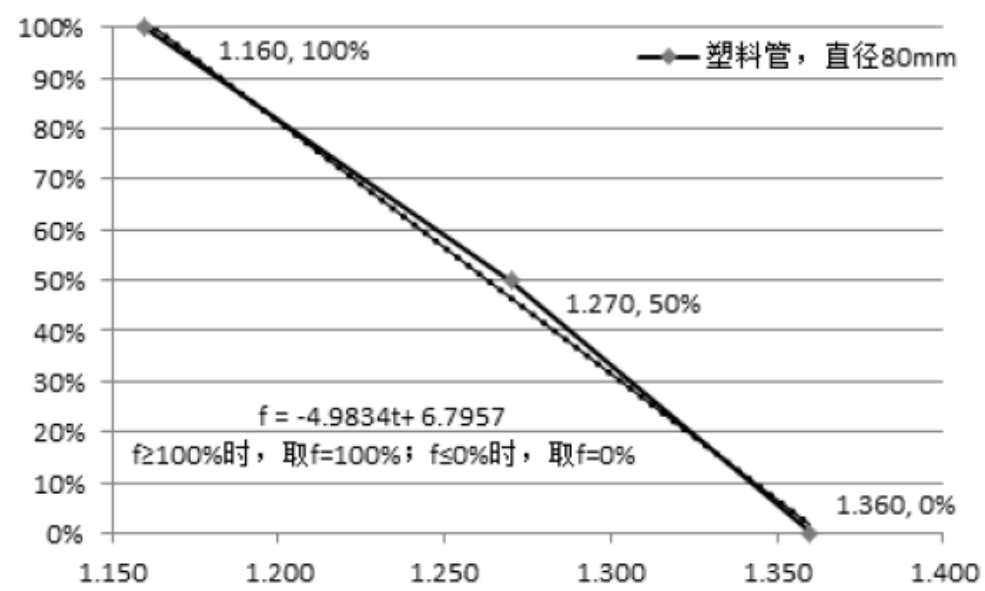

Fig. 3. The fitting curve of grouting plumpness

\section{The degree of grouting of pre-stressed pipe}

According to the calculation model of the degree of saturation of the pre-stressed pipe, the grouting fullness of each measuring point is calculated respectively. The grouting degree of each measuring point is connected to form the whole pipe grouting condition ${ }^{[5]}$. If the grouting fullness difference between the two adjacent points is greater than the specified ratio (usually 10\%), it is necessary to increase the number of measuring points between the two measuring points, and then connect the pipeline to reflect the state of grouting.

\section{Detection of grouting fullness of a pre-stressed concrete pipe}

A concrete member, length of $1 \mathrm{~m}$, thickness of $86 \mathrm{~cm}$, with a diameter of $80 \mathrm{~mm}$ plastic bellows. The calibration of line arrangement at the edge of the concrete component $0.15 \mathrm{~m}$ position distance, the measuring point distance is $0.1 \mathrm{~m}$. The measuring line is arranged on the upper surface of the concrete component corresponding to the middle axis of the pre-stressed pipeline, the measuring point distance is also $0.1 \mathrm{~m}$. Calibration line and measuring line adopt the same layout scheme.

Select the excitation frequency of $5.814 \mathrm{khz}$ steel hammer. The impact echo bottom contact time of 11 measuring points are demarcated. According to the impact echo bottom reflection time $\left(\mathrm{t}_{\mathrm{pi}}\right)$, It can calculate the mean time $\left(t_{p}\right)$ of reflection of impact echo. Where $t_{p}=0.449 \mathrm{~ms}$.

Select the same vibration frequency of 5.814khz steel hammer. The impact echo bottom reflection time of 11 measuring points of measuring line was measured. As shown in Table 2.

According to the bottom time $\left(\mathrm{t}_{\mathrm{i}}\right)$ of the impact echo of the measuring line and the Mean time $\left(t_{p}\right)$ of reflection of impact echo together with Calibration equation 2, the grouting fullness condition of each measuring point of pre-stressed pipe can be calculated. As shown in Table 2. 
Tab. 2. The time of bottom-finding reflection and the condition of grouting fullness

\begin{tabular}{|c|c|c|c|}
\hline $\begin{array}{c}\text { Measuring point } \\
\text { number i }\end{array}$ & $\begin{array}{c}\text { he impact echo } \\
\text { bottom reflection } \\
\left.\text { time } \mathrm{t}_{\mathrm{pi}} \text { (Unit: } \mathrm{ms}\right)\end{array}$ & $\begin{array}{c}\text { the impact echo } \\
\text { bottom reflection } \\
\text { time } \mathrm{t}_{\mathrm{i}} \text { (Unit: ms) }\end{array}$ & $\begin{array}{c}\text { The degree of } \\
\text { grouting fullness of } \\
\text { each measuring point } \\
\text { of pre-stressed } \\
\text { pipeline } \mathrm{f}\end{array}$ \\
\hline 1 & 0.451 & 0.532 & $89 \%$ \\
\hline 2 & 0.450 & 0.536 & $85 \%$ \\
\hline 3 & 0.450 & 0.538 & $82 \%$ \\
\hline 4 & 0.449 & 0.541 & $79 \%$ \\
\hline 5 & 0.448 & 0.543 & $77 \%$ \\
\hline 6 & 0.450 & 0.545 & $76 \%$ \\
\hline 7 & 0.449 & 0.544 & $80 \%$ \\
\hline 8 & 0.449 & 0.540 & $85 \%$ \\
\hline 9 & 0.447 & 0.536 & $89 \%$ \\
\hline 10 & 0.448 & 0.532 & $91 \%$ \\
\hline 11 & 0.449 & 0.530 & \\
\hline
\end{tabular}

As can be seen from table 2: The difference between the two measuring points is less than or equal to the specified ratio of $10 \%$. The average pressure value of each measuring point is taken as the average value, and the grouting condition of the whole pipeline is formed.

\section{Analysis of measurement error of grouting fullness}

The impact drill is used to drill holes on the pre-stressed pipe, and the grouting degree of the pre-stressed pipeline is verified. As shown in Table 3, the measurement error of pre-stressed pipe grouting fullness is better than $5 \%$. 
Tab.3 Measurement error of the grouting fullness degree

\begin{tabular}{|c|c|c|c|}
\hline $\begin{array}{c}\text { Measuring point } \\
\text { number i }\end{array}$ & $\begin{array}{c}\text { The degree of } \\
\text { grouting fullness of } \\
\text { each measuring point } \\
\text { of pre-stressed } \\
\text { pipeline f calculated } \\
\text { value }\end{array}$ & $\begin{array}{c}\text { The degree of } \\
\text { grouting fullness of } \\
\text { each measuring point } \\
\text { of pre-stressed } \\
\text { pipeline f Verification } \\
\text { value }\end{array}$ & $\begin{array}{c}\text { Relative error of } \\
\text { measurement }\end{array}$ \\
\hline 1 & $89 \%$ & $90 \%$ & $1 \%$ \\
\hline 2 & $85 \%$ & $81 \%$ & $5 \%$ \\
\hline 3 & $82 \%$ & $85 \%$ & $3 \%$ \\
\hline 4 & $79 \%$ & $81 \%$ & $4 \%$ \\
\hline 5 & $77 \%$ & $80 \%$ & $4 \%$ \\
\hline 6 & $75 \%$ & $78 \%$ & $2 \%$ \\
\hline 7 & $76 \%$ & $77 \%$ & $3 \%$ \\
\hline 8 & $80 \%$ & $78 \%$ & $5 \%$ \\
\hline 9 & $89 \%$ & $81 \%$ & $5 \%$ \\
\hline 10 & & $85 \%$ & $5 \%$ \\
\hline 11 & $81 \%$ & $87 \%$ & \\
\hline
\end{tabular}

\section{Conclusion}

In this paper, based on the principle of impact echo, a relational model between grouting fullness of pre-stressed pipe and impact echo bottom reflection time is established, and grouting fullness of pre-stressed pipe is measured quantitatively. It solves the problem that the impact echo method can only be used to determine the defect qualitatively in the existing technology and the results of test have low reliability. Using the method of this paper, the relative error of the measurement of pre-stressed pipe grouting fullness is better than $5 \%$ under test conditions. Considering the complex structure of bridge, it is necessary to study the influence of ordinary steel bars, concrete internal defects and multi row pipes on the test results. Through the establishment of the revised model to ensure the accuracy of the test and then put into Existing bridges.

\section{References:}

[1] XIN Gongfeng, WANG Zhaoxing, LIU Jiahai, et al. Research on grouting density inspection of box girder prestressedduct[J].Journal of Highway and Transportation Research and Development, 2010, 27(9): 114-117.

[2] LUAN Jian. Experimental researehes on grout quality detection of tendon ducts[D]. Changsha: Central South University of Forestry and Technology. School of Civil Engineering and Mechanics, 2011: 53-70.

[3] ZOU Chunjiang, CHEN Zhengzhou, DONG Ping, et al.Impact-echo characteristic frequencies response to groutingfullness in ducts of prestressed box beam and application[J].Journal of Highway and Transportation Research andDevelopment, 2010, 27(1): 72-77.

[4] WU Jiaye, YANG Chao, JI Wenhong, et al. Comparison of test methods for bolt\&anchor filling percentage $[\mathrm{J}]$. Journal of Sichuan University of Science\& Engineering: Natural Science Edition, 
2010, 23(5): 500-503.

[5]Ata N, Mihara S, Ohtsu M. Imaging of ungrouted tendon ductsin prestressed concrete by improved SIBIE[J]. NDT \&E International, 2007, 40(3): 258-264. 